\title{
A systematic review of the efficacy and safety of fluoridation
}

\section{Australian National Health and Medical Research Council. Canberra: Australian Government; 2007}

Scope and purpose The systematic review was commissioned by the Australian National Health and Medical Research Council (NHMRC) to evaluate the scientific literature relating to the health effects of fluoride and fluoridation. The systematic review's research questions relate to the caries-reducing benefits and associated potential health risks of providing fluoride systemically (via addition to water, milk and salt) and the use of topical fluoride agents, such as toothpaste, gel, varnish and mouthrinse. Although the review summarises the recent evidence, it does not constitute health policy or clinical practice recommendations.

Data sources A literature search was undertaken using the Medline and Embase databases (via www.embase.com). In addition, the Cochrane Systematic Review and Clinical Trial databases were searched to help identify additional systematic reviews and original studies. Because of the availability of recent systematic reviews, searches were limited to publications from 1996 onwards. The search was conducted in December 2006 and limited to English-language publications.

Study selection Based on types of intervention (individual or population) and the outcomes assessed (efficacy or safety), the hierarchy of study types considered most relevant for answering each of the clinical questions defined in this review was chosen (Table 1). The levels of evidence used by NHMRC for intervention and aetiological studies are summarised in Table 2.

Data extraction and synthesis Screening of eligible studies was conducted by three reviewers. Data were extracted for all of the included systematic reviews and individual studies using standardised data-extraction forms. This included information about the study design, NHMRC level of evidence, population, intervention, comparator, outcome definitions and results. Information relating to potential biases and study quality were also extracted. Where appropriate, study results were pooled using standard meta-analysis techniques.

Results In total, 5418 nonduplicate citations were identified. After applying the inclusion and exclusion criteria, 408 citations were considered potentially eligible for inclusion in the review. After the review of the full papers of potentially eligible articles, 77 citations were included in the review. The summary of findings was presented in the context of the research questions (Table 3).

Recommendations Fluoridation of drinking water remains the most effective and socially equitable means of achieving community-wide exposure to the caries prevention effects of fluoride. It is recommended (see also www.nhmrc.gov.au/news/media/rel07/_files/fluoride_flyer.pdf) that water be fluoridated in the target range of $0.6-1.1 \mathrm{mg} / \mathrm{l}$, depending on the climate, to balance reduction of dental caries and occurrence of dental fluorosis.n particular with reference to care in hospital for those following stroke.

Address for correspondence: National Health and Medical Research Council, GPO Box 1421, Canberra ACT 2601, Australia. E-mail: nhmrc.publications@nhmrc.gov.au

\section{Commentary}

This systematic review of fluoridation is the fourth of the reviews commissioned by the NHMRC in Australia. The first two were carried out in $1985^{4}$ and $1991^{5}$ and focussed on the effectiveness of water fluoridation. The third one ${ }^{6}$ included a review of fluoride intake from discretionary fluoride supplements in addition to water fluoridation. The third review was published in 1999, and is presently available on the website of Australian Dental Association (www.ada.org.au/app_ cmslib/media/lib/0703/m50958_v1_nhmrc\%20fluoride.pdf). The fourth review ${ }^{7}$ published in 2007 has once again expanded its scope by including other methods of fluoride delivery, such as milk, salt, toothpaste, gel, varnish and mouthrinse. Fluoride supplements such as drops, chewable tablets and chewing gum tablets have not been explicitly included in the current review, however.

The aim of the most recent review was to synthesise the highest level of evidence to answer each clinical question. It should be noted that the levels of evidence accepted for fluoride intervention at the population level was based on those chosen for the systematic review of water fluoridation by McDonagh et al. ${ }^{2}$

The inclusion and exclusion criteria for the current review were explicit. The search strategy used to identify relevant studies could not be considered to be comprehensive as no controlled vocabulary was used in searching the electronic databases. Moreover, the range of electronic databases searched was rather limited and restricting studies to those published in the English language may also affect the findings. During the literature search, three reviewers assessed the eligibility of abstracts (approximately one third each). It is not clear whether study selection or data extraction was carried out independently or in duplicate.

Included studies were clearly laid out in table format in the appendix. This included information about the study design, population, intervention, comparator, outcomes and results. The quality of studies was assessed using the key questions from the NHMRC. ${ }^{7}$ For those study designs such as cross-sectional studies and ecological studies which had no guidance on assessment from the NHMRC, a summary of various factors relating to potential biases was provided. In addition, a global quality rating was given to each individual study. Posthoc statistical analysis was carried out when necessary.

Two systematic reviews ${ }^{2,8}$ and one additional, relevant, original study ${ }^{9}$ were identified in the literature search on water fluoridation and dental caries. The York review ${ }^{2}$ was chosen to form the evidence base for the effect of water fluoridation on dental caries in the current review, as it provided more detailed and comprehensive results than those shown in the review by Truman et al. ${ }^{6}$ It should be noted that 12 of the 21 studies included in the latter were among the 26 studies included in the York review. ${ }^{2}$ The lack of overlap between the two reviews is largely because the Truman review ${ }^{8}$ assessed both "fluoridation vs no fluoridation" and "fluoridation $v s$ fluoridation at a lower level" whereas the York review ${ }^{5}$ assessed only "fluorida- 


\section{CARIES}

Table 1. Hierarchy of evidence accepted for each clinical question

\begin{tabular}{|c|c|c|}
\hline & \multicolumn{2}{|l|}{ Study levels for effect: } \\
\hline & $\begin{array}{l}\text { Intervention } \\
\text { (prevention of dental caries or dental fluorosis) }\end{array}$ & $\begin{array}{l}\text { Aetiology/ harms } \\
\text { (fracture, cancer or other adverse effects) }\end{array}$ \\
\hline \multicolumn{3}{|c|}{ Population level intervention } \\
\hline $\begin{array}{l}\text { Water fluoridation } \\
\text { Milk fluoridation } \\
\text { Salt fluoridation }\end{array}$ & $\begin{array}{l}\text { Cohort study (level III-2) } \\
\text { Case-control study (level III-2) } \\
\text { Comparative cross-sectional study I }{ }^{* \dagger} \text { (level IV) }\end{array}$ & $\begin{array}{l}\text { Prospective cohort study (level II) } \\
\text { Retrospective cohort study (level III-2) } \\
\text { Case-control study (level III-3) } \\
\text { Comparative cross-sectional study I* (level IV) } \\
\text { Comparative cross-sectional study II (level IV) }\end{array}$ \\
\hline \multicolumn{3}{|c|}{ Individual level intervention } \\
\hline Topical & RCT (level II) & $\begin{array}{l}\text { RCT (level II-intervention) } \\
\text { Retrospective cohort study (level III-2) } \\
\text { Case-control study (level III-3) } \\
\text { Comparative cross-sectional study I* (level IV) } \\
\text { Comparative cross-sectional study II (level IV) }\end{array}$ \\
\hline
\end{tabular}

RCT, Randomised controlled trial.

*Evaluated at multiple timepoints (for caries assessment), with baseline assessment associated closely with the implementation/ cessation of intervention and the final assessment at a time sufficient for the intervention to have had an effect on the outcome under investigation.

${ }^{\dagger}$ Evaluated at a single timepoint (for fluorosis, and other harms assessment) with sufficient time for intervention to have had effect on the outcome under investigation.

\section{Table 2. Hierarchy of evidence}

\begin{tabular}{|c|c|c|}
\hline Level & Intervention* & Aetiology/ harms ${ }^{\dagger}$ \\
\hline $1^{\ddagger}$ & Systematic review of level II studies & Systematic review of level II studies \\
\hline II & $\mathrm{RCT}$ & Prospective cohort study \\
\hline III-1 & A pseudo-RCT (alternate allocation of some other method) & All or noneף \\
\hline III-2 & $\begin{array}{l}\text { A comparative study with concurrent controls } \\
\text { Non-randomised experimental trial }{ }^{\S} \\
\text { Cohort study } \\
\text { Case-control study } \\
\text { Interrupted time series with a control group }\end{array}$ & A retrospective cohort study \\
\hline III-3 & $\begin{array}{l}\text { A comparative study without concurrent controls } \\
\text { Historical control study } \\
\text { Two or more single arm studies** }\end{array}$ & A case-control study \\
\hline IV & Case series with either pre-test/ post-test outcomes & A cross-sectional study \\
\hline
\end{tabular}

RCT, Randomised controlled trial.

*Definitions of these studies are provided by the NMHRC. ${ }^{1}$

$\dagger$ If it is possible and/or ethical to determine a causal relationship using experimental evidence, then the intervention hierarchy of evidence should be utilised. If it is only possible and/ or ethical to determine a causal relationship using observational evidence (ie, groups cannot be allocated to a potentially harmful exposure), then the aetiology hierarchy of evidence should be utilised.

¥A systematic review will only be assigned a level of evidence as high as the studies it contains, excepting where those studies are of level II evidence.

IAll or none of the people with risk factor(s) experience the outcome, eg, no smallpox develops in absence of specific virus and clear proof of causal link has come from the disappearance of smallpox after large-scale vaccination.

§This also includes controlled before-and-after (pre-test/ post-test) studies, as well as indirect comparisons (ie, utilise A vs B and B vs C, to determine A vs C).

${ }^{* *}$ Comparing single-arm studies (ie, case-series from two studies).

tion vs no fluoridation". Only one additional original study ${ }^{9}$ was identified in the current review and this did not change the conclusion from that of the York one. ${ }^{2}$ It should be noted that the benefits from fluoridated public water supply were weakened because bever- ages and food products processed in fluoridated communities were exported to surrounding non-fluoridated communities. ${ }^{10}$ This phenomenon is referred to as the halo effect: Griffin et al. ${ }^{11}$ attempted to quantify it by analysing data from the 1986-1987 National Survey of 
Oral Health in US School Children. Studies measuring the effectiveness of water fluoridation that consider only its direct benefit may have underestimated the total contribution of water fluoridation to caries reduction.

Regarding water fluoridation and dental fluorosis, the literature search identified two systematic reviews ${ }^{2,12}$ and 10 additional original studies. It should be noted that in some cases there was a substantial difference in the prevalence of "any fluorosis," both between different countries and within different countries. These differences result from a number of factors including methods (eg, different fluorosis indices), environmental influences (eg, phosphate mines) and lifestyles (eg, higher tea consumption). The authors concluded that although there was a fourfold risk of developing fluorosis of aesthetic concern with optimal water fluoridation compared with suboptimal water fluoridation, the absolute increase in prevalence was small (approx. 4-5\%).

The studies cited in the report of the National Research Council ${ }^{13}$ have raised the possibility that infants could receive a greater than optimal amount of fluoride through liquid concentrate or powdered baby formula that has been mixed with water containing fluoride during a time when their developing teeth may be susceptible to dental fluorosis. Recently, a systematic review to investigate the association of fluorosis and infant formula has been completed. ${ }^{14}$ It concluded that the evidence suggests dental fluorosis might be caused by fluoride content in infant formula or the fluoride levels in the water used to reconstitute infant formula. Confounding factors could not be ruled out, however, and publication bias may also distort the evidence on infant formula and fluorosis.

Although the current review presents a summary of the relevant evidence, the potential effectiveness of any public health intervention must be considered in the context of practicalities associated with implementing the intervention, issues surrounding compliance, and issues related to equity of access.

\section{Albert Yeung}

Department of Public Health, National Health Service

Lanarkshire, Hamilton, Lanarkshire, Scotland, UK

1. National Health and Medical Research Council. How to Use the Evidence: Assessment and Application of Scientific Evidence. Canberra: National Health and Medical Research Council; 2000.

2. McDonagh $M$, Whiting $P$, Bradley $M$, et al. A systematic review of public water fluoridation. York: University of York National Health Service Centre for Reviews and Dissemination; 2000.

3. Bassin EB, Wypij D, Davis RB, Mittleman MA. Age-specific fluoride exposure in drinking water and osteosarcoma (United States). Cancer Causes Control 2006; 17:421-428.

4. National Health and Medical Research Council. Review of the Safety and Effectiveness of Water Fluoridation. Canberra: National Health and Medical Research Council; 1985.

5. National Health and Medical Research Council. The Effectiveness of Water Fluoridation. Canberra: National Health and Medical Research Council; 1991.

6. National Health and Medical Research Council. Review of Water Fluoridation and Fluoride Intake from Discretionary Fluoride Supplements. Melbourne: National Health and Medical Research Council; 1999.

7. National Health and Medical Research Council. NHMRC Public Statement: the Efficacy and Safety of Fluoridation. Canberra: National Health and Medical Research Council; 2007.

8. Truman BI, Gooch BF, Sulemana I, et al. Reviews of evidence on interventions to prevent dental caries, oral and pharyngeal cancers, and sports-related craniofacial injuries. Am J Preventive Med 2002; 23(suppl. 1):S21-S54.

9. Seppä L, Kärkkäinen S, Hausen H. Caries trends 1992-1998 in two low-fluoride Finnish towns formerly with and without fluoridation. Caries Res 2000; 34:462-468.

10. Ripa LW. A half-century of community water fluoridation in the United States: review and commentary. J Public Health Dent 1993; 53:17-44.

11. Griffin SO, Gooch BF, Lockwood SA, Tomar SL. Quantifying the diffused benefit from water fluoridation in the United States. Community Dent Oral Epidemiol 2001; 29:120-129.

12. Khan A, Moola MH, Cleaton-Jones P. Global trends in dental fluorosis from 1980 to 2000: a systematic review. South African Dent J 2005; 60:418-421.

13. Committee on Fluoride in Drinking Water, National Research Council. Fluoride in Drinking Water: a Scientific Review of EPA's standards. Washington: National Academies Press; 2006.

14. Zina LG, Hujoel P, Moimaz SAS, Cunha-Cruz J. Infant formula and fluorosis: a systematic review (abstract). J Dent Res 2008; 87(special issue): no.1144.

Evidence-Based Dentistry (2008) 9, 39-43. doi:10.1038/sj.ebd.6400578

Table 3. Summary of findings in context of research questions

\begin{tabular}{|c|c|c|}
\hline Benefit/ risk & Question & Findings \\
\hline \multicolumn{3}{|l|}{ Dental caries } \\
\hline Water fluoridation & $\begin{array}{l}\text { Is intentional water fluoridation more } \\
\text { effective than no water fluoridation in } \\
\text { prevention of dental caries? }\end{array}$ & $\begin{array}{l}\text { Existing evidence strongly suggests water fluoridation is beneficial at reducing } \\
\text { dental caries. After adjustment for potential confounding variables, it was } \\
\text { shown }{ }^{2} \text { that introducing water fluoridation into an area significantly increased } \\
\text { proportion of caries-free children, and decreased mean dmft/DMFT scores vs } \\
\text { areas that were non-fluoridated over the same time period. These findings }{ }^{2} \text { also } \\
\text { suggest cessation of fluoridation resulted in the difference in caries prevalence } \\
\text { narrowing between fluoridated and nonfluoridated populations. Only one } \\
\text { additional relevant original study was identified in the current review, which did } \\
\text { not change the conclusion. }\end{array}$ \\
\hline Milk fluoridation & $\begin{array}{l}\text { Is intentional milk fluoridation more } \\
\text { effective than no milk fluoridation in } \\
\text { prevention of dental caries? }\end{array}$ & $\begin{array}{l}\text { Results of the SR suggest milk fluoridation is beneficial in preventing/ reducing } \\
\text { caries but there is less good quality evidence than for water fluoridation. Results } \\
\text { of two original studies included represent low levels of evidence but results are } \\
\text { consistent with milk fluoridation being associated with caries prevention and } \\
\text { cessation of milk fluoridation with worsening dental health. }\end{array}$ \\
\hline Salt fluoridation & $\begin{array}{l}\text { Is intentional salt fluoridation more } \\
\text { effective than no salt fluoridation in } \\
\text { prevention of dental caries? }\end{array}$ & $\begin{array}{l}\text { No studies were identified that met criteria for inclusion in review. Results of } \\
\text { three before-and-after cross-sectional studies suggest salt fluoridation reduces } \\
\text { caries in populations of children of age } 6-15 \text { years. Note that these studies were } \\
\text { considered of poor methodological quality because of lack of assessment of and } \\
\text { adjustment for potential confounding factors. }\end{array}$ \\
\hline
\end{tabular}




\begin{tabular}{|c|c|c|}
\hline $\begin{array}{l}\text { Topical fluoride } \\
\text { supplementation }\end{array}$ & $\begin{array}{l}\text { Is use of topical fluoride } \\
\text { supplementation more efficacious } \\
\text { than no topical fluoride } \\
\text { supplementation in prevention of } \\
\text { dental caries? }\end{array}$ & $\begin{array}{l}\text { There is consistent level I evidence from existing SR and a review of additional } \\
\text { original studies that topical fluoride agents reduce caries in children vs no topical } \\
\text { fluoride supplementation. Compared with placebo/ no treatment, magnitude } \\
\text { of the effect achieved with varnish is greater than other topical agents but when } \\
\text { compared directly there is no significant difference between agents. }\end{array}$ \\
\hline $\begin{array}{l}\text { Combination of topical } \\
\text { fluoride supplementation }\end{array}$ & $\begin{array}{l}\text { Is a combination of topical fluoride } \\
\text { supplementation products more } \\
\text { efficacious than a single topical } \\
\text { fluoride supplement product in } \\
\text { prevention of dental caries? }\end{array}$ & $\begin{array}{l}\text { There is level I evidence that some combinations of topical agents may be more } \\
\text { effective at preventing/ reducing caries than single agents. }\end{array}$ \\
\hline \multicolumn{3}{|l|}{ Dental fluorosis } \\
\hline Water fluoridation & $\begin{array}{l}\text { Does intentional water fluoridation } \\
\text { result in dental fluorosis over and above } \\
\text { no intentional water fluoridation? }\end{array}$ & $\begin{array}{l}\text { There is consistent level III/IV evidence from existing SR that water fluoridation } \\
\text { results in development of dental fluorosis but most of it is mild and not considered } \\
\text { to be of aesthetic concern. The NNH with water fluoridation at an optimal level } \\
\text { vs no fluoridation to get one additional person with any fluorosis is approx. } 6 \text {. } \\
\text { The corresponding NNH to get one additional person with fluorosis of aesthetic } \\
\text { concern is approx. 22. Meta-analysis of additional original studies provides results } \\
\text { consistent with those seen in the existing SR. }\end{array}$ \\
\hline Milk fluoridation & $\begin{array}{l}\text { Does intentional milk fluoridation } \\
\text { result in dental fluorosis over and } \\
\text { above no intentional milk fluoridation? }\end{array}$ & $\begin{array}{l}\text { One study provided level IV evidence that milk fluoridation is not associated with } \\
\text { significant levels of fluorosis. A statistically significant increase in fluorosis was seen } \\
\text { in a number of age groups following introduction of milk fluoridation but the } \\
\text { majority of this fluorosis was mild and not considered to be of aesthetic concern. }\end{array}$ \\
\hline Salt fluoridation & $\begin{array}{l}\text { Does intentional salt fluoridation result } \\
\text { in dental fluorosis over and above no } \\
\text { intentional salt fluoridation? }\end{array}$ & $\begin{array}{l}\text { One level IV study provided evidence of a significantly increased risk of "any } \\
\text { fluorosis" associated with salt fluoridation. Two additional supportive studies (not } \\
\text { strictly meeting inclusion criteria) agreed with the included study. There were no } \\
\text { data relating to risk of fluorosis of aesthetic concern. }\end{array}$ \\
\hline $\begin{array}{l}\text { Topical fluoride } \\
\text { supplementation }\end{array}$ & $\begin{array}{l}\text { Does topical fluoride supplementation } \\
\text { result in dental fluorosis over } \\
\text { and above no topical fluoride } \\
\text { supplementation? }\end{array}$ & $\begin{array}{l}\text { Two level IV studies provide evidence regarding impact of use of topical fluorides on } \\
\text { dental fluorosis. One study showed fluoridated toothpaste may be associated with } \\
\text { "any fluorosis" but when "fluorosis of aesthetic concern" was examined, no statistically } \\
\text { significant difference between higher fluoride dose and control groups was found, and } \\
\text { prevalence of fluorosis in higher dose toothpaste group was low }(<2 \%) \text {. One poor quality } \\
\text { study in which fluorosis was measured after a campaign was implemented to reduce the } \\
\text { amount of topical fluoride use in children suggested that a decrease in fluorosis was seen. }\end{array}$ \\
\hline $\begin{array}{l}\text { Combination of topical } \\
\text { fluoride supplementation }\end{array}$ & $\begin{array}{l}\text { Does a combination of topical fluoride } \\
\text { supplementation products result in dental } \\
\text { fluorosis over and above a single topical } \\
\text { fluoride supplementation product? }\end{array}$ & $\begin{array}{l}\text { There is currently no evidence comparing combinations of topical agents with a } \\
\text { single topical agent. }\end{array}$ \\
\hline \multicolumn{3}{|l|}{ Fracture or osteoporosis } \\
\hline Water fluoridation & $\begin{array}{l}\text { Does intentional water fluoridation } \\
\text { result in fracture over and above no } \\
\text { intentional water fluoridation? }\end{array}$ & $\begin{array}{l}\text { Authors of three existing SR concur that water fluoridation at levels aimed at } \\
\text { preventing dental caries has little effect on fracture risk, either protective or } \\
\text { deleterious. Results of subsequent original studies support this, but do suggest } \\
\text { optimal fluoridation levels of } 1 \text { ppm may result in a lower risk of fracture vs excessively } \\
\text { high levels (well beyond those experienced in Australia). One study also indicated } \\
\text { optimal fluoridation levels may lower overall fracture risk vs no fluoridation (the latter } \\
\text { was not the case when hip fractures were considered in isolation). }\end{array}$ \\
\hline Milk fluoridation & $\begin{array}{l}\text { Does intentional milk fluoridation result } \\
\text { in osteoporosis or fracture over and } \\
\text { above no intentional milk fluoridation? }\end{array}$ & $\begin{array}{l}\text { There is currently no evidence available to determine impact of milk fluoridation } \\
\text { upon fracture risk. }\end{array}$ \\
\hline Salt fluoridation & $\begin{array}{l}\text { Does intentional salt fluoridation result } \\
\text { in osteoporosis or fracture over and } \\
\text { above no intentional salt fluoridation? }\end{array}$ & $\begin{array}{l}\text { There is currently no evidence available to determine impact of salt fluoridation } \\
\text { upon fracture risk. }\end{array}$ \\
\hline $\begin{array}{l}\text { Topical fluoride } \\
\text { supplementation }\end{array}$ & $\begin{array}{l}\text { Does topical fluoride supplementation } \\
\text { result in osteoporosis or fracture } \\
\text { over and above no topical fluoride } \\
\text { supplementation? }\end{array}$ & $\begin{array}{l}\text { There is currently no evidence available to determine impact of topical fluoride } \\
\text { supplementation upon fracture risk. }\end{array}$ \\
\hline
\end{tabular}


Combination of topical fluoride supplementation

ran

\section{Cancer}

\begin{tabular}{l|l} 
Water fluoridation & $\begin{array}{l}\text { Does intentional water fluoridation } \\
\text { increase risk of cancer over and abo }\end{array}$
\end{tabular}
increase risk of cancer over and above no intentional water fluoridation?
Does a combination of topical result in osteoporosis or fracture over and above a single topical fluoride supplementation product?
There is currently no evidence available to determine impact of combination topical fluoride supplementation upon fracture risk.

\begin{tabular}{c} 
Combination of topical \\
fluoride supplementation \\
\hline Topical fluoride \\
\hline Milk fluoridation
\end{tabular}

fluoride supplementation

Does intentional milk fluoridation increase risk of cancer over and above no intentional milk fluoridation?

Does intentional salt fluoridation increase risk of cancer over and above no intentional salt fluoridation?

Does topical fluoride supplementation increase risk of cancer over and above no topical fluoride supplementation?

Does a combination of topical fluoride supplementation products increase risk of cancer over and above a single topical fluoride supplementation product?

The existing $\mathrm{SR}^{2}$ concluded there is no clear association between water fluoridation and overall cancer incidence or mortality (for "all cause" cancer, and specifically for bone cancer and osteosarcoma). The authors state that evidence relating fluoridation to cancer incidence or mortality is mixed, with small variations on either side of the effect. The current literature review identified four additional studies investigating relationship between water fluoridation and cancer incidence or mortality, including three level IV ecological studies and one level II-3 matched case-control study. ${ }^{3}$ The latter study compares fluoride exposure of histologically-confirmed osteosarcoma cases with that of matched controls (subset of patients from larger case-control study by Harvard School of Dental Medicine yet to report its findings). After adjusting for significant differences at baseline between cases and controls, results ${ }^{3}$ suggest an increased risk of osteosarcoma in young males (not females) with water fluoridation but note the letter from co-investigators which points out that they have not been able to replicate these findings in the broader Harvard study which included prospective cases from the same 11 hospitals. The bone samples taken in the broader study also corroborate a lack of association between fluoride content in drinking water and osteosarcoma in new cases. The full study is not yet published and the letter's authors caution readers not to over-interpret results ${ }^{3}$ in the interim.

There is currently no evidence available to determine impact of milk fluoridation upon cancer risk.

There is currently no evidence available to determine impact of salt fluoridation upon cancer risk.

There is currently no evidence available to determine impact of topical fluoride supplementation upon cancer risk.

There is currently no evidence available to determine impact of combination topical fluoride supplementation upon cancer risk.

\section{Other adverse effects}

Water fluoridation

Milk fluoridation

Salt fluoridation

Topical fluoride supplementation

Combination of topica fluoride supplementation
Is intentional water fluoridation associated with other adverse effects over and above no intentional water fluoridation?

Is intentional milk fluoridation associated with other adverse effect over and above no intentional milk fluoridation?

Is intentional salt fluoridation associated with other adverse effects over and above no intentional salt fluoridation?

Is topical fluoride supplementation associated with other adverse effects over and above no topical fluoride supplementation?

Is a combination of topical fluoride supplementation products associated with other adverse effects over and above a single topical fluoride supplementation product
Authors of previous SR concluded that studies examining other possible negative effects of water fluoridation provide insufficient evidence to reach a conclusion.

There is currently no evidence available to determine impact of milk fluoridation upon other harms.

There is currently no evidence available to determine impact of salt fluoridation upon other harms.

There is currently no evidence available to determine impact of topical fluorides upon other harms.

There is currently no evidence available to determine impact of combination topical fluorides upon other harms.

dmft/DMFT, Decayed, missing or filled teeth of the primary or permanent dentition; SR, systematic review; NNH, number needed to harm. 